\title{
p53, a potential predictor of Helicobacter pylori infection- associated gastric carcinogenesis?
}

\author{
Nianshuang $\mathrm{Li}^{1, *}$, Chuan Xie ${ }^{1, *}$ and Nong-Hua Lu ${ }^{1}$ \\ ${ }^{1}$ Department of Gastroenterology, The First Affiliated Hospital of Nanchang University, Nanchang, Jiangxi, China \\ ${ }^{*}$ These authors have contributed equally to the review and writing of this manuscript
}

Correspondence to: Nong-Hua Lu, email: lunonghua@ncu.edu.cn

Keywords: Helicobacter pylori; p53; tumourigenesis

Received: May 08, $2016 \quad$ Accepted: August 13, $2016 \quad$ Published: August 19, 2016

\section{ABSTRACT}

Helicobacter pylori (H. pylori) is an ancient and persistent inhabitant of the human stomach that is closely linked to the development of gastric cancer (GC). . Emerging evidence suggests that $\boldsymbol{H}$. pylori strain interactions with gastric epithelial cells subvert the best- characterized p53 tumour suppressor pathway. A high prevalence of p53 mutations is related to $H$. pylori infection. $H$. pylori also accelerates p53 protein degradation by disturbing the MDM2-P53 feedback loop. Additionally, $\boldsymbol{H}$. pylori triggers the alteration of other p53 isoforms. Dysregulation of p53 by $\boldsymbol{H}$. pylori infection contributes to gastric carcinogenesis by mediating cell proliferation and apoptosis. This review focuses on the regulation of p53 in $\mathrm{H}$. pylori infectionassociated GC.

\section{INTRODUCTION}

Helicobacter pylori infection is a strong risk factor for gastric cancer (GC). The International Agency for Research on Cancer (IARC) classified this bacterium as a Group I carcinogen. Epidemiological studies indicate that approximately $50 \%$ of the global population is infected with $H$. pylori, which is primarily acquired during childhood [1-3]. H. pylori uses various virulence factors in gastric epithelial cells to target different signalling pathways that regulate specialized survival programs, such as the cell cycle and apoptosis. Vacuolating cytotoxin gene (vacA) and cag pathogenicity island (cagPAI) are the best characterized virulence factors [4]. cagPAI encodes a type IV secretion system (T4SS) that delivers the oncoprotein CagA into host cells.

Chronic inflammation results from the virulence factor CagA and is recognized as the underlying mechanism of $H$. pylori-associated gastric carcinogenesis [5]. Accumulating data demonstrate that CagA injection into host cells stimulates the recruitment of inflammatory cells and the production of cytokines, including interleukin (IL) $-1 \beta$ and IL- 8 , as well as the activation of $\mathrm{Wnt} / \beta$ catenin signalling via the nuclear accumulation of betacatenin in epithelial cells [6-8]. H. pylori also promotes PI3K/AKT, mTOR, and p38/MAPK signalling, and these oncogenic signalling pathways alter cellular oncogenes and tumour suppressors. H. pylori also disrupts cell-cell junctions and cell polarity via inhibition of the PAR-1/ MARK complex $[9,10]$. H. pylori infection causes DNA double-strand breaks (DSBs) and genomic instability via the generation of reactive oxygen species (ROS) and reactive nitrogen species (RNS) $[11,12]$. Together, recent studies have shown that the regulation of p53 is involved in gastric carcinogenesis caused by $H$. pylori infection.

The pathogenic bacterium $H$. pylori modulates the host p53 pathway by controlling various cellular stresses, including DNA damage, ROS and RNS production, and abnormal oncogene activation. Frequent p53 gene mutations are also detected in gastric pre-neoplastic lesions, which more broadly suggests an association between p53 and disturbances in cell proliferation and apoptosis in gastric epithelial cells infected with $H$. pylori. This review focuses on $H$. pylori infection-mediated p53 regulation because of the central role of p53 in $H$. pyloriinduced gastric carcinogenesis. Thus, p53 may serve as a novel biomarker and therapeutic target for GC.

\section{TUMOUR SUPPRESSOR P53}

The human tumour suppressor gene p53, also known as TP53, was first identified in 1979 as a cellular protein bound to immunoprecipitates of the SV40 LT protein in SV40 tumour virus-transformed cells [13]. The p53 is 
present at extremely low levels in normal cells, but these levels increase significantly in response to DNA damage or other types of cellular stress [14]. In particular, DNA damage induces the stabilization and nuclear accumulation of p53 via the DNA damage signalling pathway, which involves sensor kinases such as ataxia-telangiectasia mutated (ATM) and ataxia-telangiectasia and Rad3-related (ATR) [15, 16].

p53 is known as the "guardian of the genome" because it repairs DNA and maintains genomic stability after DNA damage. The ubiquitin ligases murine double minute (MDM2, also known as HDM2) and ARF-BP1 are crucial negative regulators of p53 that drive its rapid degradation [17, 18]. Notably, p14ARF regulates the transcriptional activity of p53 by antagonizing MDM2. The p53 protein functions as a transcription factor that promotes cell cycle arrest at the G1 phase via upregulation of the expression of an inhibitor of cyclin-dependent kinase, p21. p53 also induces cell apoptosis via two apoptotic pathways, the mitochondrial pathway, which mediates the expression of B-cell lymphoma 2 (Bcl-2) family members, and the death receptor pathway, which triggers activation of the caspase cascade [19-21] (Figure 1). Indeed, approximately $50 \%$ of all cancers exhibit a mutation in p53 [22]. In vivo assays have shown that mice expressing a mutant p53 protein exhibit more aggressive and metastatic tumours compared to p53 wild-type (WTp53) mice [23]. These findings suggest that the mutation of p53 during tumourigenesis represents an essential step in the switch to aggressive tumour development.

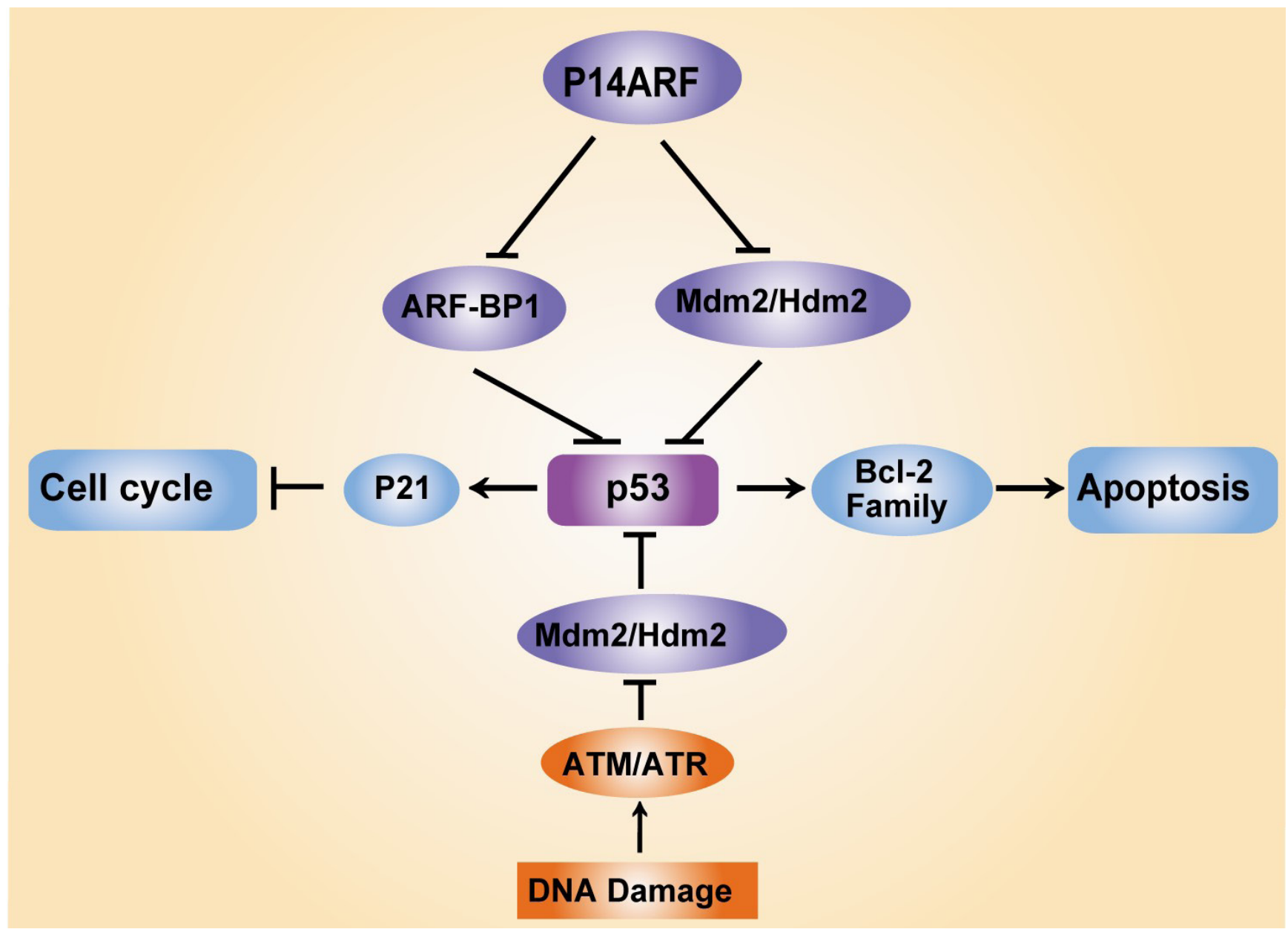

Figure 1: Regulation of p53 and its key regulators in response to DNA damage. DNA damage triggers the activation of the tumour suppressor protein p53 via ataxia-telangiectasia mutated (ATM) and ataxia-telangiectasia and Rad3-related (ATR) protein kinase-dependent pathways, which leads to cell cycle arrest via the induction of the cyclin-dependent kinase (CDK) inhibitor p21 and cell apoptosis via mediation of Bcl-2 family expression. MDM2 (also known as HDM2) and ARF-BP1 act as E3 ubiquitin ligases that target p53 proteasomal degradation, which ensures low p53 levels in normal and unstressed cells. Notably, the tumour suppressor p14ARF protects p53 protein stability via inhibition of MDM2/HDM2 and ARFBP1. 


\section{EXPRESSION OF P53 IN H. PYLORI- INFECTED PATIENTS WITH GASTRIC CARCINOGENESIS}

GC is divided into three pathological variants: intestinal type, diffuse type and mixed type [24, 25]. H. pylori has been identified as the strongest risk factor of intestinal type GC, which may progress from atrophy gastritis to intestinal metaplasia, dysplasia and eventually carcinoma [26]. Some investigations have detected p53 expression in the gastric mucosa of patients with pre-neoplastic lesions infected with $H$. pylori, including atrophy and intestinal metaplasia [27, 28]. Immunohistochemical analyses of p53 in CagA-positive H. pylori gastritis patients prior to gastric metaplastic/ dysplastic changes have revealed increased $\mathrm{p} 53$ expression but decreased apoptosis, and one possible cause for this association is the detection of mutant p53 protein [29]. p53, p21 and Ki-67 expression were examined using immunohistochemical staining in volunteers from the general Spanish population. The subjects with $H$. pylori infection exhibited significantly higher p53 levels and mucosal proliferative activity compared to the uninfected subjects, and this association was primarily related to cardia-type mucosa rather than corpus [30]. A 3-month prospective study was performed to classify the relationship between $H$. pylori infection and p53 in patients with intestinal metaplasia, and the results indicated an obvious association of $H$. pylori infection with $\mathrm{p} 53$ expression [31].

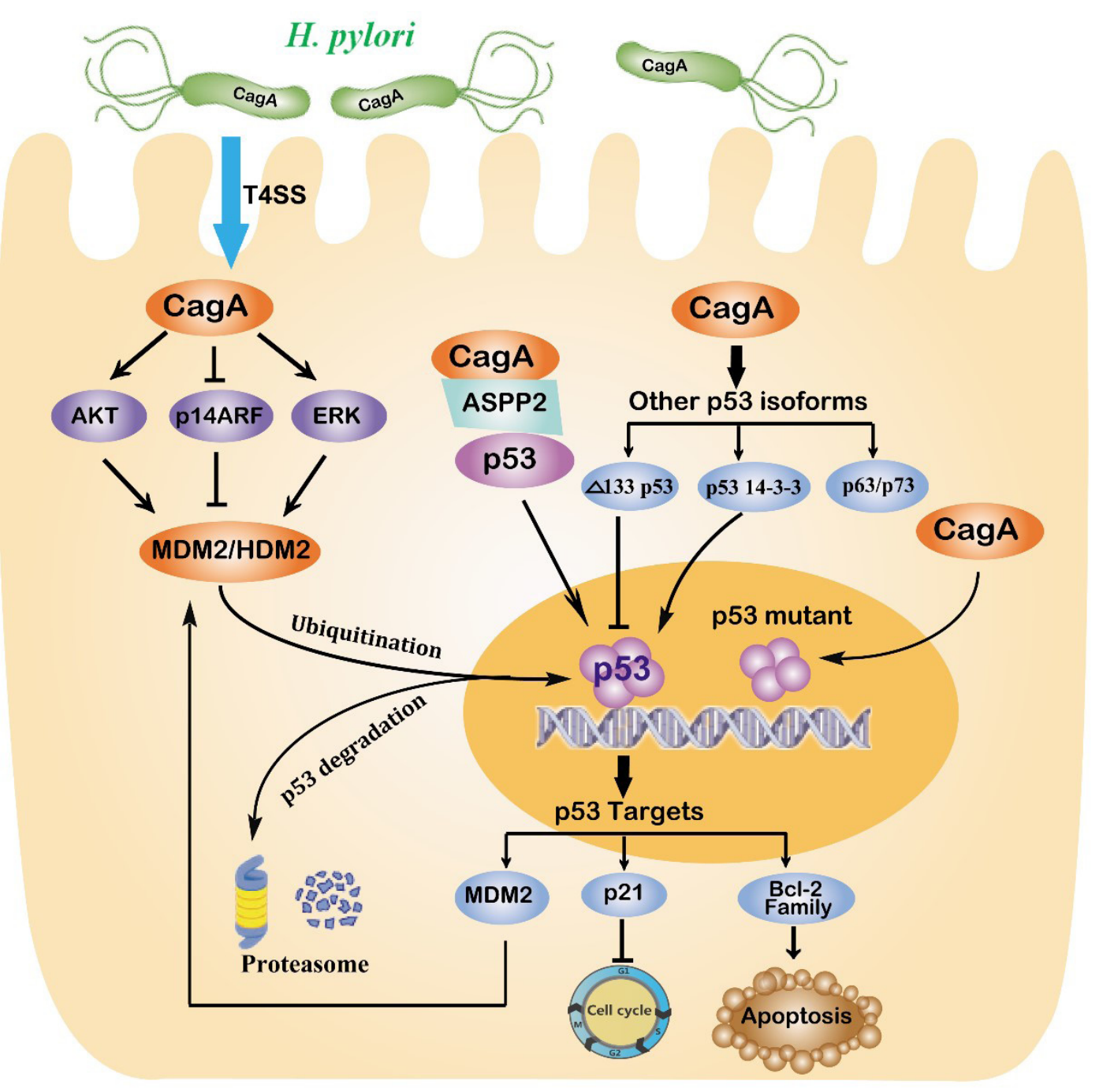

Figure 2: Regulation of p53 in gastric carcinogenesis induced by $\boldsymbol{H}$. pylori. $H$. pylori injects the oncoprotein CagA into gastric epithelial cells using a type IV secretion system (T4SS), which is responsible for alterations of the tumour suppressor p53. Chronic $H$. pylori infection may cause an accumulation of mutant p53. H. pylori also increases MDM2 levels via multiple mechanisms that target the proteasome-mediated degradation of $\mathrm{p} 53$. The CagA protein also binds to the apoptosis-stimulating protein of p53 (ASPP), which consequently hinders the interaction between ASPP2 and p53. Other isoforms of the p53 family, including p63, p73, $\Delta 133 \mathrm{p} 53$ and p53 143-3 protein isoforms, are also involved in the regulation of $\mathrm{p} 53$ by H. pylori. In summary, long-term infection with $H$. pylori is responsible for reducing the levels of 553 , which contributes to the development of gastric carcinoma. 
Wild-type p53 protein is relatively unstable and generally not detectable. In contrast, mutant $\mathrm{p} 53$ exhibits a much longer half-life, and immunohistochemical staining of p53 is commonly used as a surrogate for mutational analyses [32]. Gastric biopsy samples from gastritis, intestinal metaplasia and GC patients were collected to measure p53 expression levels in gastric carcinogenesis related to $H$. pylori infection. p53 protein exhibited a significantly higher degree of staining in $H$. pylori-positive GC samples; specifically, p53-positive cells were identified in $0 \%$ of control samples, $0 \%$ of gastritis samples, $13.3 \%$ of intestinal metaplasia samples and $43 \%$ of GC samples $[33,34]$. These results suggest that alteration of $\mathrm{p} 53$ may be an early event in $\mathrm{H}$. pyloriassociated gastric carcinogenesis.

\section{P53 GENE MUTATIONS RELATED TO $H$. PYLORI INFECTION}

Inactivation of the tumour suppressor p53 is a hallmark of tumourigenic changes. Accordingly, the p53 gene is aberrantly expressed in nearly half of all human cancer cell genomes. Mutant p53 proteins acquire tumour-promoting functions that enhance cell growth, proliferation, survival, and motility $[35,36]$ p53 mutations are generally divided into two categories: DNA-interacting mutants that directly alter amino acids and structural mutants that lead to the unfolding of p53 protein, which is critical for tumours to gain tumour-associated functional phenotypes [37, 38]. Notably, the primary alterations of p53 occur primarily in highly conserved domains, especially amino acid substitutions, including R175, G245, R248, R249, R273 and R282. Some mutant p53 proteins that recognize a unique response element acquire properties of an oncogenic transcription factor. Mutant p53 was experimentally demonstrated to deregulate checkpoints of cell cycle responses to the induction of DNA damage, which accelerated tumour progression via the promotion of genomic instability, cell proliferation and invasion $[39,40]$.

Numerous studies have shown that $H$. pylori infection is associated with a higher prevalence of p53 mutation. Indeed, an increasing frequency of p53 alterations occurs in neoplastic gastric lesions ranging from gastritis through dysplasia, intestinal metaplasia ( IM ) and advanced GC [41-43]. H. pylori is the strongest risk factor for $\mathrm{GC}$, and this infection is known to enhance p53 mutagenesis. Lopez-Saez et al. found that $81 \%$ of the H. pylori-associated GC deaths in Spain were associated with increased mutant $\mathrm{p} 53$ protein compared to $11 \%$ in the H. pylori-negative group[44]. H. pylori infection may also contribute to the development of gastric adenocarcinoma by elevating mutant $\mathrm{p} 53$ protein [45]. The accumulation of mutant p 53 may be attributed to the production of free radicals, such as ROS and RNS [46]. The combination of whole-exome sequencing with deep sequencing revealed that $\mathrm{C}: \mathrm{G}>\mathrm{T}: \mathrm{A}$ transitions at $\mathrm{XpCpG}$ trinucleotides were the most common accumulation pattern of TP53. A total of $105 \mathrm{GC}$ specimens from a high-risk area in Italy were examined for the prevalence of p53 mutations [47]. Notably, an association of $H$. pylori infection with p53 mutations was also apparent at $\mathrm{CpG}$ sites[47].

Mutations of p53 in exon 5-8 nucleotide sequences have also been widely studied in primary gastric adenocarcinoma with $H$. pylori infection [48]. Nucleotide sequencing analyses demonstrated the induction of several point mutations in exons 5, 6, 7 and 8 of the p53 gene in $H$. pylori-infected monkeys compared to H. pyloriuninfected monkeys, and p53 gene mutations were closely related to the degree of gastric mucosa atrophy [49]. Alterations in exons 5-8 of the p53 gene were also observed in $H$. pylori-positive patients with $\mathrm{GC}$ and peptic ulcer disease (PUD) [50, 51]. The well-characterized factor CagA is an important virulence determinant in the gastric carcinogenesis of $H$. pylori infection. Notably, the p53 gene is more likely to harbour p53 mutations in gastric tumours with CagA-positive H. pylori strains. Recent studies suggest that gastric epithelial cells infected with CagA-positive H. pylori induce the expression of cytidine deaminase (AID), which may be a mechanism of p53 mutation accumulation during $H$. pylori-associated gastric carcinogenesis [28, 52].

\section{P53 CODON 72 POLYMORPHISMS}

Several polymorphic sites in the tumour suppressor p53 are closely associated with various cancer risks. The codon 72 polymorphism that produces variant genotypes with arginine (Arg) or proline (Pro) is a frequently reported polymorphism site [53-55]. Hiyama et al. demonstrated that Pro/Pro genotypes at the p53 codon 72 polymorphism contribute to susceptibility to diffuse-type gastric carcinoma in patients with chronic gastritis [56]. One study reported that the polymorphism is related to lower TP53 transcriptional levels [55]. The distribution of the p53 codon 72 polymorphism varies in different regions worldwide. PCR-Taqman assays identified the Arg/Pro genotype of the p53 codon 72 polymorphism in 140 patients with gastric carcinoma from the GanSu province in China, where the GC incidence is high, and the p53 codon 72 Pro carrier genotype with $H$. pylori infection was consistently higher in GC groups than controls [57]. The p53 Pro/Arg and p53 Arg/Arg single-nucleotide polymorphism (SNP) variants were also significantly more common than the $\mathrm{p} 53$ Pro/Pro variant in a population from North India, which exhibits a high prevalence of $H$. pylori infection but low GC incidence. Therefore, the Arg or Pro/ Arg polymorphism may underlie these differences [58]. 


\section{REGULATION OF THE P53-MDM2 FEEDBACK LOOP}

The p53 pathway is extremely sensitive to DNA double-strand breaks (DSBs) and single-stranded DNA (ssDNA) gaps, which are created by a variety of DNA-damaging agents, including ionizing radiation, chemotherapeutic drugs and ultraviolet (UV) radiation [59, 60]. The transcription-activating powers of p53 depend on the regulation of ATM and ATR protein kinases, which transfer the p53 signals to cell cycle checkpoint 1 (Chk1) and cell cycle checkpoint 2 (Chk2) kinases and lead to the phosphorylation of $\mathrm{p} 53$ to protect it from destruction by the specific E3 ubiquitin ligase murine double minute 2 (MDM2) [61, 62].

The MDM2 protein has emerged as a crucial regulator of $\mathrm{p} 53$ tumour suppressor function. MDM2 binding to $\mathrm{p} 53$ immediately induces proteasome degradation of p53 and blocks p53-driven transcription $[17,63]$. The underlying molecular mechanism of MDM2 regulation of p53 degradation has been elucidated; MDM2 binds to the $\mathrm{N}$ terminus of $\mathrm{p} 53$ and promotes its export from the nucleus to cytoplasm, which results in its rapid degradation in cytoplasmic proteasomes [64]. p53 elements are located in the promoter of MDM2, and p53 induces the expression of MDM2. Therefore, a negative feedback loop exists between $\mathrm{p} 53$ and MDM2 that ensures low cellular p53 levels in normal and unstressed cells [65].

The amplification and overexpression of MDM2 are frequently observed in a variety of human cancers [66, 67], and $H$. pylori also suppresses p53 through multiple mechanisms [68]. This bacterium contributes to proteasomal degradation of p53 by increasing the phosphorylation of the E3 ubiquitin ligase MDM2 [69, 70]. Indeed, elevated levels of MDM2 are found in $H$. pylori-infected intestinal metaplasia and GC [71]. p53 was also shown to be upregulated in a bimodal fashion over time in Mongolian gerbils, which are the most suitable laboratory animal model for the study of $H$. pylori infection $[69,72]$. Acute accumulation of $\mathrm{p} 53$ was observed in response to cellular stressors after initial $H$. pylori infection, with subsequent rapid downregulation of p53 in the gastric mucosa; a second peak of p53 occurred after gastritis development [73]. These studies suggest that alterations in $\mathrm{p} 53$ expression profiles depend on the duration of $H$. pylori infection.

\section{UPSTREAM REGULATORS OF THE MDM2-P53 FEEDBACK LOOP IN THE PATHOGENESIS OF H. PYLORI}

H. pylori infection increases the phosphorylation and activation of AKT and MDM2 to downregulate p53, which results in the inactivation of $\mathrm{p} 53$ by increased ubiquitination and proteasome degradation $[74,75]$. Our previous studies investigated the correlation between protein expression in the AKT-MDM2-p53 pathway and $H$. pylori infection in chronic non-atrophic gastritis (CNAG), metaplastic atrophy (MA), gastric dysplasia (Dys) and GC patients. Notably, higher levels of mutant p53 and MDM2 were observed in H. pylori-positive patients with MA and Dys, and the expression of phosphorylated AKT was upregulated in CNAG patients with $H$. pylori infection. The expression of pAKT and MDM2 was also significantly increased after $H$. pylori strains were co-cultured with GES-1 gastric epithelial cells, which also supports the degradation of $\mathrm{p} 53[76,77]$. Inhibition of MDM2 activity using siRNA or the inhibitor Nutlin3 in AGS human GC cells clearly inhibited the downregulation of $H$. pylori-induced p53. Notably, the bacterial protein CagA plays an important role in the alteration of $\mathrm{p} 53$ protein, as ectopic expression of $\mathrm{CagA}$ is sufficient to enhance AKT and MDM2 activity and induce p53 degradation $[73,77]$.

ERK kinase interactions with HDM2 are responsible for p53 activity in H. pylori-infected cells [78], and experimental inhibition of ERK/MDM2 interactions was shown to rescue p53 activity and dampen damaged cell survival [79]. The intercellular junction protein E-cadherin, which maintains the epithelial barrier, was also upregulated in these gastric epithelial cells. AKT and ERK contribute to MDM2 activation in the setting of $H$. pylori infection, which leads to degradation of the p53 protein. Notably, p53 was dynamically altered in gastric epithelial cells co-cultured with $H$. pylori, which suggests a crucial role of the p53-MDM2 feedback loop [80].

P14ARF inhibits cell proliferation in a p53dependent manner. Specifically, p14ARF segregates MDM2 in the nucleolus and antagonizes the E3 ubiquitin ligase-mediated $\mathrm{p} 53$ protein degradation [81, 82]. H. pylori contains high levels of bacterial CagA protein, which rapidly induce $\mathrm{p} 53$ degradation, although $\mathrm{p} 53$ is protected by thetumour suppressor p14ARF. The oncogenic strain 7.13 of $H$. pylori efficiently induces gastric dysplasia and adenocarcinoma, and this strain was significantly more potent in attenuating the expression of p14ARF and p53 compared to the non-tumourigenic strain B128. These results were confirmed in gastric epithelial cells by the ectopic expression of protein or the downregulation of ARF using shRNA [83]. The p14ARF gene promoter is frequently methylated during the development of GC, and the $\mathrm{p} 53$ protein is rapidly degraded as a result[84].

\section{OTHER P53 ISOFORMS REGULATED BY H. PYLORI INFECTION}

p63 and p73 are homologues of the p53 gene [85], and the high sequence similarity of their DNA-binding domain allows p63 and p73 to regulate p53-dependent cell cycle and apoptosis in response to DNA damage [86]. The $\mathrm{P} 1$ and $\mathrm{P} 2$ promoters of $\mathrm{p} 63$ and $\mathrm{p} 73$ promote 
the expression of a variety of protein isoforms, including the TA isoforms (TAp63 and TAp73) with an N-terminal transactivation domain (TAD) and the $\Delta \mathrm{N}$ isoforms with diametrically opposed functions $(\Delta \mathrm{Np} 63$ and $\Delta \mathrm{Np} 73)$ without the TAD $[87,88]$. Elevated levels of p73 have been reported in $H$. pylori-positive human and murine tissues, and in vitro assays have demonstrated the role of p73 in the pathogenesis of H. pylori infection. AGS cell lines co-cultured with $H$. pylori exhibited significantly increased TAp73 expression, while $\Delta \mathrm{Np} 63$ expression was suppressed. These findings were also confirmed using dominant-negative p73 mutants[89].

$\Delta 133 \mathrm{p} 53$ is a truncated p53 isoform that is altered after $H$. pylori infection. The alternative promoter of the p53 gene, upstream of exon 1, or an internal promoter located in intron 4 results in an N-terminally truncated p53 protein initiated at codon $133(\Delta 133$ p53) [90]. Growing evidence demonstrates that $\Delta 133 \mathrm{p} 53$ is overexpressed in several tumour types $[91,92]$. Wei et al. demonstrated that H. pylori infection induced $\Delta 133 \mathrm{p} 53$ expression in AGS and SNU-1 gastric epithelial cells, and these findings were also observed in Mongolian gerbils. These cell lines were transfected with the endogenous $\Delta 133$ p53 isoform shRNA plasmid, and the $\Delta 133 \mathrm{p} 53$ isoforms affected the activity of p53 and p73, leading to the upregulation of the p53 target proteins p21 and phorbol-12-myristate13-acetate-induced protein 1 (PMAIP1; also known as NOXA). Mechanistically, the activator protein-1 (AP1) transcriptional complex, which is composed of c-Fos and c-Jun proteins, is also involved in the regulation of $\Delta 133$ p53 in $H$. pylori cells $[93,94]$. This finding is consistent with previous studies showing that $H$. pylori accelerated the progression to gastric intraepithelial neoplasia via the upregulation of AP-1 and NF- $\kappa$ B activity [95]. Notably, cagPAI is required for the regulation of p53 isoforms by $H$. pylori.

The p53 14-3-3 protein isoform binds to the regulatory $\mathrm{C}$-terminal domain of $\mathrm{p} 53$, and this binding is subverted in $H$. pylori-associated gastritis and GC [96]. The p53 14-3-3 proteins are a class of adaptor proteins with seven isoforms $(\beta, \gamma, \varepsilon, \eta, \sigma, \tau$, and $\zeta)$ that stabilize the tumour suppressor p53 and enhance its biological activity [96]. Proteasome and immunohistochemistry analyses have demonstrated that AGS cell lines show reduced

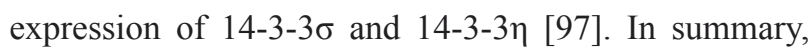
these studies suggest that p53 isoforms represent novel components of the host-defence mechanism and play an important role in $H$. pylori-associated cell proliferation and apoptosis.

\section{REGULATION OF THE APOPTOSIS- STIMULATING PROTEIN OF P53 (ASPP) FAMILY IN H. PYLORI-RELATED CARCINOGENESIS}

The ASPP family functions as a key regulator of $\mathrm{p} 53$, and it consists of three members: ASPP1, ASPP2, and iASPP [98]. ASPP1 and ASPP2 enhance the ability of p53 to stimulate the expression of pro-apoptotic factors, such as Bax and p53-upregulated modulator of apoptosis (PUMA) [99]. Conversely, iASPP is a key inhibitor of p53 [100]. The apoptosis activator ASPP2 was downregulated and the apoptosis suppressor iASPP was upregulated in H. pylori-positive gastric carcinoma and pre-cancerous lesion tissues, which suggests that the ASPP family plays an important role in the gastric carcinogenesis of $\mathrm{H}$. pylori infection [101].

The cancer-associated effector of the $H$. pylori CagA protein binds to residues 448-692 and 693-918 of ASPP2 [102]. After translocation into host epithelial cells, CagA induces the relocalization of ASPP2 rather than its abnormal expression and hinders the interaction between ASPP2 and p53, which is responsible for $H$. pylori-induced degradation of $\mathrm{p} 53$ and resistance to the apoptotic response [103, 104]. Suppression of apoptosis then contributes to the development of gastric dysplasia and adenocarcinoma [105]. This finding may be in conflict with previous studies showing that $H$. pylori infection stimulates host gastric epithelial cell apoptosis. However, the effect of cell apoptosis may be associated with continued $H$. pylori colonization, and a variety of genes are known to regulate cell apoptosis. Together, these findings show that the $H$. pylori CagA protein interaction with ASPP2 subverts the function of ASPP2 and p53, which facilitates $H$. pylori-induced gastric carcinogenesis.

\section{CONCLUSIONS}

Infection with $H$. pylori leads to the aberrant expression of p53 protein through the induction of host DNA damage. The tumour suppressor p53 plays a major role in determining multiple signalling pathways and cellular responses. Chronic infection with the bacterial pathogen $H$. pylori may attenuate $\mathrm{p} 53$ levels via augmentation of $\mathrm{p} 53$ mutations, proteasome degradation and post-transcriptional modification. Furthermore, the expression of p53 transcriptional targets is inhibited and results in excessive proliferation and impaired apoptosis, which contributes to a greater risk of gastric carcinoma. Therefore, alterations of p53 may serve as a potential marker of $H$. pylori-associated gastric carcinogenesis.

\section{CONFLICTS OF INTEREST}

The authors declare no competing financial interests. 


\section{GRANT SUPPORT}

This work was financially supported by grants from the National Natural Science Foundation of China (Nos. 81060038 and 81270479), the Jiangxi Province Talent 555 Project, and the National Science and Technology Major Projects for "Major New Drugs Innovation and Development" of China (No. 2011ZX09302-007-03).

\section{REFERENCES}

1. Polk DB and Peek RM, Jr. Helicobacter pylori: gastric cancer and beyond. Nature reviews Cancer. 2010; 10:403414.

2. Salama NR, Hartung ML and Muller A. Life in the human stomach: persistence strategies of the bacterial pathogen Helicobacter pylori. Nature reviews Microbiology. 2013; 11:385-399.

3. Amieva M and Peek RM, Jr. Pathobiology of Helicobacter pylori-induced gastric cancer. Gastroenterology. 2015; 150:64-78.

4. Franco AT, Johnston E, Krishna U, Yamaoka Y, Israel DA, Nagy TA, Wroblewski LE, Piazuelo MB, Correa P and Peek RM, Jr. Regulation of gastric carcinogenesis by Helicobacter pylori virulence factors. Cancer research. 2008; 68:379-387.

5. Suzuki M, Mimuro H, Kiga K, Fukumatsu M, Ishijima N, Morikawa H, Nagai S, Koyasu S, Gilman RH, Kersulyte D, Berg DE and Sasakawa C. Helicobacter pylori CagA phosphorylation-independent function in epithelial proliferation and inflammation. Cell host \& microbe. 2009; 5:23-34.

6. Franco AT, Israel DA, Washington MK, Krishna U, Fox JG, Rogers AB, Neish AS, Collier-Hyams L, Perez-Perez GI, Hatakeyama M, Whitehead R, Gaus K, O'Brien DP, Romero-Gallo $\mathrm{J}$ and Peek RM, Jr. Activation of betacatenin by carcinogenic Helicobacter pylori. Proceedings of the National Academy of Sciences of the United States of America. 2005; 102:10646-10651.

7. Neal JT, Peterson TS, Kent ML and Guillemin K. H. pylori virulence factor CagA increases intestinal cell proliferation by Wnt pathway activation in a transgenic zebrafish model. Disease models \& mechanisms. 2013; 6:802-810.

8. Koch M, Mollenkopf HJ and Meyer TF. Macrophages recognize the Helicobacter pylori type IV secretion system in the absence of toll-like receptor signalling. Cellular microbiology. 2016; 18:137-147.

9. Saadat I, Higashi H, Obuse C, Umeda M, Murata-Kamiya N, Saito Y, Lu H, Ohnishi N, Azuma T, Suzuki A, Ohno $\mathrm{S}$ and Hatakeyama M. Helicobacter pylori CagA targets PAR1/MARK kinase to disrupt epithelial cell polarity. Nature. 2007; 447:330-333.

10. Nesic D, Miller MC, Quinkert ZT, Stein M, Chait BT and Stebbins CE. Helicobacter pylori CagA inhibits PAR1-
MARK family kinases by mimicking host substrates. Nature structural \& molecular biology. 2010; 17:130-132.

11. Toller IM, Neelsen KJ, Steger M, Hartung ML, Hottiger MO, Stucki M, Kalali B, Gerhard M, Sartori AA, Lopes $\mathrm{M}$ and Muller A. Carcinogenic bacterial pathogen Helicobacter pylori triggers DNA double-strand breaks and a DNA damage response in its host cells. Proceedings of the National Academy of Sciences of the United States of America. 2011; 108:14944-14949.

12. Hanada K, Uchida T, Tsukamoto Y, Watada M, Yamaguchi N, Yamamoto K, Shiota S, Moriyama M, Graham DY and Yamaoka Y. Helicobacter pylori infection introduces DNA double-strand breaks in host cells. Infection and immunity. 2014; 82:4182-4189.

13. Linzer DI and Levine AJ. Characterization of a $54 \mathrm{~K}$ dalton cellular SV40 tumor antigen present in SV40-transformed cells and uninfected embryonal carcinoma cells. Cell. 1979; $17: 43-52$.

14. Sakaguchi K, Herrera JE, Saito S, Miki T, Bustin M, Vassilev A, Anderson CW and Appella E. DNA damage activates p53 through a phosphorylation-acetylation cascade. Genes \& development. 1998; 12:2831-2841.

15. Tibbetts RS, Brumbaugh KM, Williams JM, Sarkaria JN, Cliby WA, Shieh SY, Taya Y, Prives C and Abraham RT. A role for ATR in the DNA damage-induced phosphorylation of p53. Genes \& development. 1999; 13:152-157.

16. Giaccia AJ and Kastan MB. The complexity of p53 modulation: emerging patterns from divergent signals. Genes \& development. 1998; 12:2973-2983.

17. Meng X, Franklin DA, Dong J and Zhang Y. MDM2-p53 pathway in hepatocellular carcinoma. Cancer research. 2014; 74:7161-7167.

18. Chen D, Kon N, Li M, Zhang W, Qin J and Gu W. ARF-BP1/Mule is a critical mediator of the ARF tumor suppressor. Cell. 2005; 121:1071-1083.

19. Sherr CJ and McCormick F. The RB and p53 pathways in cancer. Cancer cell. 2002; 2:103-112.

20. Gartel AL, Serfas MS and Tyner AL. p21-negative regulator of the cell cycle. Proceedings of the Society for Experimental Biology and Medicine Society for Experimental Biology and Medicine. 1996; 213:138-149.

21. Miyashita T and Reed JC. Tumor suppressor p53 is a direct transcriptional activator of the human bax gene. Cell. 1995; 80:293-299.

22. Soussi $\mathrm{T}$ and Wiman KG. Shaping genetic alterations in human cancer: the p53 mutation paradigm. Cancer cell. 2007; 12:303-312.

23. Kenzelmann Broz D and Attardi LD. In vivo analysis of p53 tumor suppressor function using genetically engineered mouse models. Carcinogenesis. 2010; 31:1311-1318.

24. Zheng HC, Li XH, Hara T, Masuda S, Yang XH, Guan YF and Takano Y. Mixed-type gastric carcinomas exhibit more aggressive features and indicate the histogenesis of 
carcinomas. Virchows Arch. 2008; 452:525-534.

25. Hu B, El Hajj N, Sittler S, Lammert N, Barnes R and Meloni-Ehrig A. Gastric cancer: Classification, histology and application of molecular pathology. J Gastrointest Oncol. 2012; 3:251-261.

26. Correa P. Human gastric carcinogenesis: a multistep and multifactorial process-First American Cancer Society Award Lecture on Cancer Epidemiology and Prevention. Cancer research. 1992; 52:6735-6740.

27. Satoh K, Kihira K, Kawata H, Tokumaru K, Kumakura Y, Ishino Y, Kawakami S, Inoue K, Kojima T, Satoh Y, Mutoh H and Sugano K. p53 expression in the gastric mucosa before and after eradication of Helicobacter pylori. Helicobacter. 2001; 6:31-36.

28. Shimizu T, Marusawa H, Matsumoto Y, Inuzuka T, Ikeda A, Fujii Y, Minamiguchi S, Miyamoto S, Kou T, Sakai Y, Crabtree JE and Chiba T. Accumulation of somatic mutations in TP53 in gastric epithelium with Helicobacter pylori infection. Gastroenterology. 2014; 147:407-417 e403.

29. Teh M, Tan KB, Seet BL and Yeoh KG. Study of p53 immunostaining in the gastric epithelium of cagA-positive and cagA-negative Helicobacter pylori gastritis. Cancer. 2002; 95:499-505.

30. Petersson F, Franzen LE and Borch K. Characterization of the gastric cardia in volunteers from the general population. Type of mucosa, Helicobacter pylori infection, inflammation, mucosal proliferative activity, p53 and p21 expression, and relations to gastritis. Digestive diseases and sciences. 2010; 55:46-53.

31. Morales-Fuentes GA, Zarate-Osorno A, Quinonez-Urrego EE, Antonio-Manrique M, Martinez-Garcia CL, FigueroaBarojas P, Zamorano-Orozco Y, Leal-Osuna SE, MartinezCamacho C, Mejia-Cuan LA, Rivera-Nava CA, SanchezChavez X and Ramirez-Ramirez MA. [p53 expression in the gastric mucosa of patients infected with Helicobacter pylori]. Revista de gastroenterologia de Mexico. 2013; 78:12-20.

32. Yemelyanova A, Vang R, Kshirsagar M, Lu D, Marks MA, Shih Ie M and Kurman RJ. Immunohistochemical staining patterns of p53 can serve as a surrogate marker for TP53 mutations in ovarian carcinoma: an immunohistochemical and nucleotide sequencing analysis. Modern pathology. $2011 ; 24: 1248-1253$.

33. Li JH, Shi XZ, Lv S, Liu M and Xu GW. Effect of Helicobacter pylori infection on $\mathrm{p} 53$ expression of gastric mucosa and adenocarcinoma with microsatellite instability. World journal of gastroenterology. 2005; 11:4363-4366.

34. Salih BA, Gucin Z and Bayyurt N. A study on the effect of Helicobacter pylori infection on p53 expression in gastric cancer and gastritis tissues. Journal of infection in developing countries. 2013; 7:651-657.

35. Kalo E, Kogan-Sakin I, Solomon H, Bar-Nathan E, Shay M, Shetzer Y, Dekel E, Goldfinger N, Buganim Y, Stambolsky
P, Goldstein I, Madar S and Rotter V. Mutant p53R273H attenuates the expression of phase 2 detoxifying enzymes and promotes the survival of cells with high levels of reactive oxygen species. Journal of cell science. 2012; 125:5578-5586.

36. Weissmueller S, Manchado E, Saborowski M, Morris JPt, Wagenblast E, Davis CA, Moon SH, Pfister NT, Tschaharganeh DF, Kitzing T, Aust D, Markert EK, Wu J, Grimmond SM, Pilarsky C, Prives C, et al. Mutant p53 drives pancreatic cancer metastasis through cellautonomous PDGF receptor beta signaling. Cell. 2014; 157:382-394.

37. Liu DP, Song $\mathrm{H}$ and $\mathrm{Xu} \mathrm{Y}$. A common gain of function of p53 cancer mutants in inducing genetic instability. Oncogene. 2010; 29:949-956.

38. Kato S, Han SY, Liu W, Otsuka K, Shibata H, Kanamaru $\mathrm{R}$ and Ishioka $\mathrm{C}$. Understanding the function-structure and function-mutation relationships of p53 tumor suppressor protein by high-resolution missense mutation analysis. Proceedings of the National Academy of Sciences of the United States of America. 2003; 100:8424-8429.

39. Oren $M$ and Rotter V. Mutant p53 gain-of-function in cancer. Cold Spring Harbor perspectives in biology. 2010; 2:a001107.

40. Weisz L, Oren M and Rotter V. Transcription regulation by mutant p53. Oncogene. 2007; 26:2202-2211.

41. Kanda M, Sadakari Y, Borges M, Topazian M, Farrell J, Syngal S, Lee J, Kamel I, Lennon AM, Knight S, Fujiwara S, Hruban RH, Canto MI and Goggins M. Mutant TP53 in duodenal samples of pancreatic juice from patients with pancreatic cancer or high-grade dysplasia. Clinical gastroenterology and hepatology. 2013; 11:719-730.e715.

42. Busuttil RA, Zapparoli GV, Haupt S, Fennell C, Wong SQ, Pang JM, Takeno EA, Mitchell C, Di Costanzo N, Fox S, Haupt Y, Dobrovic A and Boussioutas A. Role of p53 in the progression of gastric cancer. Oncotarget. 2014; 5:1201612026. doi:10.18632/oncotarget.2434.

43. Zheng Y, Wang L, Zhang JP, Yang JY, Zhao ZM and Zhang XY. Expression of p53, c-erbB-2 and Ki67 in intestinal metaplasia and gastric carcinoma. World journal of gastroenterology. 2010; 16:339-344.

44. Lopez-Saez JB, Gomez-Biondi V, Santamaria-Rodriguez G, Dominguez-Villar M, Amaya-Vidal A, Lorenzo-Penuelas A and Senra-Varela A. Concurrent overexpression of serum p53 mutation related with Helicobacter pylori infection. Journal of experimental \& clinical cancer research. 2010; 29:65.

45. Derks S and Bass AJ. Mutational signatures in Helicobacter pylori-induced gastric cancer: lessons from new sequencing technologies. Gastroenterology. 2014; 147:267-269.

46. Khromova NV, Kopnin PB, Stepanova EV, Agapova LS and Kopnin BP. p53 hot-spot mutants increase tumor vascularization via ROS-mediated activation of the HIF1/ VEGF-A pathway. Cancer letters. 2009; 276:143-151. 
47. Palli D, Caporaso NE, Shiao YH, Saieva C, Amorosi A, Masala G, Rice JM and Fraumeni JF, Jr. Diet, Helicobacter pylori, and p53 mutations in gastric cancer: a molecular epidemiology study in Italy. Cancer epidemiology, biomarkers \& prevention. 1997; 6:1065-1069.

48. Shibata A, Parsonnet J, Longacre TA, Garcia MI, Puligandla B, Davis RE, Vogelman JH, Orentreich N and Habel LA. CagA status of Helicobacter pylori infection and p53 gene mutations in gastric adenocarcinoma. Carcinogenesis. 2002; 23:419-424

49. Oda T, Murakami K, Nishizono A, Kodama M, Nasu M and Fujioka T. Long-term Helicobacter pylori infection in Japanese monkeys induces atrophic gastritis and accumulation of mutations in the p53 tumor suppressor gene. Helicobacter. 2002; 7:143-151.

50. Murakami K, Fujioka T, Kodama M, Honda S, Okimoto T, Oda T, Nishizono A, Sato R, Kubota T, Kagawa J and Nasu M. Analysis of p53 mutations and Helicobacter pylori infection in human and animal models. Journal of gastroenterology. 2002; 37 Suppl 13:1-5.

51. Saxena A, Shukla SK, Prasad KN and Ghoshal UC. Analysis of p53, K-ras gene mutation \& Helicobacter pylori infection in patients with gastric cancer \& peptic ulcer disease at a tertiary care hospital in north India. The Indian journal of medical research. 2012; 136:664-670.

52. Matsumoto Y, Marusawa H, Kinoshita K, Endo Y, Kou T, Morisawa T, Azuma T, Okazaki IM, Honjo T and Chiba T. Helicobacter pylori infection triggers aberrant expression of activation-induced cytidine deaminase in gastric epithelium. Nature medicine. 2007; 13:470-476.

53. Goncalves ML, Borja SM, Cordeiro JA, Saddi VA, Ayres FM, Vilanova-Costa CA and Silva AM. Association of the TP53 codon 72 polymorphism and breast cancer risk: a meta-analysis. SpringerPlus. 2014; 3:749.

54. Wang S, Lan X, Tan S, Wang S and Li Y. P53 codon 72 Arg/Pro polymorphism and lung cancer risk in Asians: an updated meta-analysis. Tumour biology. 2013; 34:25112520 .

55. Gemignani F, Moreno V, Landi S, Moullan N, Chabrier A, Gutierrez-Enriquez S, Hall J, Guino E, Peinado MA, Capella G and Canzian F. A TP53 polymorphism is associated with increased risk of colorectal cancer and with reduced levels of TP53 mRNA. Oncogene. 2004; 23:19541956.

56. Hiyama T, Tanaka S, Kitadai Y, Ito M, Sumii M, Yoshihara M, Shimamoto F, Haruma K and Chayama K. p53 Codon 72 polymorphism in gastric cancer susceptibility in patients with Helicobacter pylori-associated chronic gastritis. International journal of cancer. 2002; 100:304-308.

57. Ke-Xiang Z, Yu-Min L, Xun L, Wen-Ce Z, Yong S and Tao L. Study on the association of $\mathrm{p} 53$ codon 72 polymorphisms with risk of gastric cancer in high incidence Hexi area of Gansu Province in China. Molecular biology reports. 2012; 39:723-728.
58. Pandey R, Misra V, Misra SP, Dwivedi M and Misra A. Helicobacter pylori infection and a P53 codon 72 single nucleotide polymorphism: a reason for an unexplained Asian enigma. Asian Pacific journal of cancer prevention. 2014; 15:9171-9176.

59. Bochkareva E, Kaustov L, Ayed A, Yi GS, Lu Y, PinedaLucena A, Liao JC, Okorokov AL, Milner J, Arrowsmith $\mathrm{CH}$ and Bochkarev A. Single-stranded DNA mimicry in the p53 transactivation domain interaction with replication protein A. Proceedings of the National Academy of Sciences of the United States of America. 2005; 102:1541215417.

60. Koeppel M, Garcia-Alcalde F, Glowinski F, Schlaermann $\mathrm{P}$ and Meyer TF. Helicobacter pylori infection causes characteristic DNA damage patterns in human cells. Cell reports. 2015; 11:1703-1713.

61. Zannini L, Delia D and Buscemi G. CHK2 kinase in the DNA damage response and beyond. Journal of molecular cell biology. 2014; 6:442-457.

62. Reinhardt HC, Aslanian AS, Lees JA and Yaffe MB. p53deficient cells rely on ATM- and ATR-mediated checkpoint signaling through the $\mathrm{p} 38 \mathrm{MAPK} / \mathrm{MK} 2$ pathway for survival after DNA damage. Cancer cell. 2007; 11:175-189.

63. Gao K, Wang C, Jin X, Xiao J, Zhang E, Yang X, Wang D, Huang H, Yu L and Zhang P. RNF12 promotes p53dependent cell growth suppression and apoptosis by targeting MDM2 for destruction. Cancer letters. 2016; 375:133-141.

64. Joseph TW, Zaika A and Moll UM. Nuclear and cytoplasmic degradation of endogenous p53 and HDM2 occurs during down-regulation of the $\mathrm{p} 53$ response after multiple types of DNA damage. FASEB journal. 2003; 17:1622-1630.

65. Moll UM and Petrenko O. The MDM2-p53 interaction. Molecular cancer research. 2003; 1:1001-1008.

66. Yu Q, Li Y, Mu K, Li Z, Meng Q, Wu X, Wang Y and Li L. Amplification of Mdmx and overexpression of MDM2 contribute to mammary carcinogenesis by substituting for p53 mutations. Diagnostic pathology. 2014; 9:71.

67. Sehdev V, Katsha A, Arras J, Peng D, Soutto M, Ecsedy J, Zaika A, Belkhiri A and El-Rifai W. HDM2 regulation by AURKA promotes cell survival in gastric cancer. Clinical cancer research. 2014; 20:76-86.

68. Yong X, Tang B, Li BS, Xie R, Hu CJ, Luo G, Qin Y, Dong $\mathrm{H}$ and Yang SM. Helicobacter pylori virulence factor CagA promotes tumorigenesis of gastric cancer via multiple signaling pathways. Cell communication and signaling. $2015 ; 13: 30$.

69. Zaika AI, Wei J, Noto JM and Peek RM. Microbial Regulation of p53 Tumor Suppressor. PLoS pathogens. 2015; 11:e1005099.

70. Kodama M, Fujioka T, Murakami K, Okimoto T, Sato R, Watanabe K and Nasu M. Eradication of Helicobacter 
pylori reduced the immunohistochemical detection of p53 and MDM2 in gastric mucosa. Journal of gastroenterology and hepatology. 2005; 20:941-946.

71. Nakajima N, Ito Y, Yokoyama K, Uno A, Kinukawa N, Nemoto $\mathrm{N}$ and Moriyama M. The Expression of Murine Double Minute 2 (MDM2) on Helicobacter pylori-Infected Intestinal Metaplasia and Gastric Cancer. Journal of clinical biochemistry and nutrition. 2009; 44:196-202.

72. Hayakawa Y, Fox JG, Gonda T, Worthley DL, Muthupalani $\mathrm{S}$ and Wang TC. Mouse models of gastric cancer. Cancers. 2013; 5:92-130.

73. Wei J, Nagy TA, Vilgelm A, Zaika E, Ogden SR, RomeroGallo J, Piazuelo MB, Correa P, Washington MK, ElRifai W, Peek RM and Zaika A. Regulation of p53 tumor suppressor by Helicobacter pylori in gastric epithelial cells. Gastroenterology. 2010; 139:1333-1343.

74. Ogawara Y, Kishishita S, Obata T, Isazawa Y, Suzuki T, Tanaka K, Masuyama N and Gotoh Y. Akt enhances Mdm2-mediated ubiquitination and degradation of $\mathrm{p} 53$. The Journal of biological chemistry. 2002; 277:21843-21850.

75. Fenouille N, Puissant A, Tichet M, Zimniak G, Abbe P, Mallavialle A, Rocchi S, Ortonne JP, Deckert M, Ballotti R and Tartare-Deckert S. SPARC functions as an anti-stress factor by inactivating p53 through Akt-mediated MDM2 phosphorylation to promote melanoma cell survival. Oncogene. 2011; 30:4887-4900.

76. Zaika AI. Bacterial pathogen Helicobacter pylori: A bad AKTor inhibits p53 protein activity [corrected]. Digestive diseases and sciences. 2015; 60:822-823.

77. Shu X, Yang Z, Li ZH, Chen L, Zhou XD, Xie Y and $\mathrm{Lu}$ NH. Helicobacter pylori infection activates the AktMdm2-p53 signaling pathway in gastric epithelial cells. Digestive diseases and sciences. 2015; 60:876-886.

78. Phillips A, Jones CJ and Blaydes JP. The mechanisms of regulation of $\mathrm{Hdm} 2$ protein level by serum growth factors. FEBS letters. 2006; 580:300-304.

79. Sato A, Sunayama J, Matsuda K, Seino S, Suzuki K, Watanabe E, Tachibana K, Tomiyama A, Kayama T and Kitanaka C. MEK-ERK signaling dictates DNA-repair gene MGMT expression and temozolomide resistance of stemlike glioblastoma cells via the MDM2-p53 axis. Stem cells. 2011; 29:1942-1951.

80. Bhardwaj V, Noto JM, Wei J, Andl C, El-Rifai W, Peek RM and Zaika AI. Helicobacter pylori bacteria alter the p53 stress response via ERK-HDM2 pathway. Oncotarget. 2015; 6:1531-1543. doi:10.18632/oncotarget.2828.

81. Shi D and Gu W. Dual Roles of MDM2 in the Regulation of p53: Ubiquitination Dependent and Ubiquitination Independent Mechanisms of MDM2 Repression of p53 Activity. Genes Cancer. 2012; 3:240-248. doi:10.1177/1947601912455199.

82. Wang J, Ding S, Duan Z, Xie Q, Zhang T, Zhang X, Wang Y, Chen X, Zhuang H and Lu F. Role of p14ARFHDM2-p53 axis in SOX6-mediated tumor suppression.
Oncogene. 2015; 35:1692-1702.

83. Wei J, Noto JM, Zaika E, Romero-Gallo J, Piazuelo MB, Schneider B, El-Rifai W, Correa P, Peek RM and Zaika AI. Bacterial CagA protein induces degradation of $\mathrm{p} 53$ protein in a p14ARF-dependent manner. Gut. 2015; 64:1040-1048.

84. Iida S, Akiyama Y, Nakajima T, Ichikawa W, Nihei Z, Sugihara K and Yuasa Y. Alterations and hypermethylation of the p14(ARF) gene in gastric cancer. International journal of cancer. 2000; 87:654-658.

85. Venkatanarayan A, Raulji P, Norton W and Flores ER. Novel therapeutic interventions for $\mathrm{p} 53$-altered tumors through manipulation of its family members, p63 and p73. Cell cycle (Georgetown, Tex). 2016; 15:164-171.

86. Moll UM and Slade N. p63 and p73: roles in development and tumor formation. Molecular cancer research. 2004; 2:371-386

87. Bourdon JC. p53 and its isoforms in cancer. British journal of cancer. 2007; 97:277-282.

88. Wei J, Zaika E and Zaika A. p53 Family: role of protein isoforms in human cancer. Journal of nucleic acids. 2012; 2012:687359.

89. Wei J, O'Brien D, Vilgelm A, Piazuelo MB, Correa P, Washington MK, El-Rifai W, Peek RM and Zaika A. Interaction of Helicobacter pylori with gastric epithelial cells is mediated by the p53 protein family. Gastroenterology. 2008; 134:1412-1423.

90. Khoury MP and Bourdon JC. p53 Isoforms: An Intracellular Microprocessor? Genes Cancer. 2011; 2:453-465. doi:10.1177/1947601911408893.

91. Nutthasirikul N, Limpaiboon T, Leelayuwat C, Patrakitkomjorn S and Jearanaikoon P. Ratio disruption of the 133p53 and TAp53 isoform equilibrium correlates with poor clinical outcome in intrahepatic cholangiocarcinoma. International journal of oncology. 2013; 42:1181-1188.

92. Slatter TL, Hung N, Bowie S, Campbell H, Rubio C, Speidel D, Wilson M, Baird M, Royds JA and Braithwaite AW. Delta122p53, a mouse model of Delta133p53alpha, enhances the tumor-suppressor activities of an attenuated p53 mutant. Cell death \& disease. 2015; 6:e1783.

93. Bossis G, Malnou CE, Farras R, Andermarcher E, Hipskind R, Rodriguez M, Schmidt D, Muller S, Jariel-Encontre I and Piechaczyk M. Down-regulation of c-Fos/c-Jun AP-1 dimer activity by sumoylation. Molecular and cellular biology. 2005; 25:6964-6979.

94. Wei J, Noto J, Zaika E, Romero-Gallo J, Correa P, ElRifai W, Peek RM and Zaika A. Pathogenic bacterium Helicobacter pylori alters the expression profile of p53 protein isoforms and p53 response to cellular stresses. Proceedings of the National Academy of Sciences of the United States of America. 2012; 109:E2543-2550.

95. Zhao XD, Lu YY, Guo H, Xie HH, He LJ, Shen GF, Zhou JF, Li T, Hu SJ, Zhou L, Han YN, Liang SL, Wang X, Wu KC, Shi YQ, Nie YZ, et al. MicroRNA-7/NF-kappaB 
signaling regulatory feedback circuit regulates gastric carcinogenesis. The Journal of cell biology. 2015; 210:613627.

96. Schumacher B, Mondry J, Thiel P, Weyand M and Ottmann C. Structure of the p53 C-terminus bound to 14-3-3: implications for stabilization of the p53 tetramer. FEBS letters. 2010; 584:1443-1448.

97. Nagappan A, Park HS, Park KI, Hong GE, Yumnam S, Lee HJ, Kim MK, Kim EH, Lee WS, Lee WJ, Cho MJ, Lee WK, Won CK, Cho JH and Kim GS. Helicobacter pylori infection combined with DENA revealed altered expression of p53 and 14-3-3 isoforms in Gulo-/- mice. Chemicobiological interactions. 2013; 206:143-152.

98. Sullivan A and Lu X. ASPP: a new family of oncogenes and tumour suppressor genes. British journal of cancer. 2007; 96:196-200.

99. Wang Y, Godin-Heymann N, Dan Wang X, Bergamaschi D, Llanos S and Lu X. ASPP1 and ASPP2 bind active RAS, potentiate RAS signalling and enhance p53 activity in cancer cells. Cell death and differentiation. 2013; 20:525534.

100. Notari M, Hu Y, Koch S, Lu M, Ratnayaka I, Zhong S, Baer C, Pagotto A, Goldin R, Salter V, Candi E, Melino G and $\mathrm{Lu} \mathrm{X}$. Inhibitor of apoptosis-stimulating protein of p53 (iASPP) prevents senescence and is required for epithelial stratification. Proceedings of the National Academy of Sciences of the United States of America. 2011; 108:1664516650.

101. Meng WD, Chu RX, Wang BZ, Wang LP, Ma LL and Wang LX. Helicobacter pylori infection and expressions of apoptosis-related proteins p53, ASPP2 and iASPP in gastric cancer and precancerous lesions. Pathol Biol. 2013; 61:199202.
102. Reingewertz TH, Iosub-Amir A, Bonsor DA, Mayer G, Amartely H, Friedler A and Sundberg EJ. An Intrinsically Disordered Region in the Proapoptotic ASPP2 Protein Binds to the Helicobacter pylori Oncoprotein CagA. Biochemistry. 2015; 54:3337-3347.

103. Buti L, Spooner E, Van der Veen AG, Rappuoli R, Covacci A and Ploegh HL. Helicobacter pylori cytotoxin-associated gene A (CagA) subverts the apoptosis-stimulating protein of p53 (ASPP2) tumor suppressor pathway of the host. Proceedings of the National Academy of Sciences of the United States of America. 2011; 108:9238-9243.

104. Nesic D, Buti L, Lu X and Stebbins CE. Structure of the Helicobacter pylori CagA oncoprotein bound to the human tumor suppressor ASPP2. Proceedings of the National Academy of Sciences of the United States of America. 2014; 111:1562-1567.

105. Hao W, Yuan X, Yu L, Gao C, Sun X, Wang D and Zheng Q. Licochalcone A-induced human gastric cancer BGC-823 cells apoptosis by regulating ROS-mediated MAPKs and PI3K/AKT signaling pathways. Scientific reports. 2015; 5:10336. 